\section{DIGITAL COMMONS \\ @ UNIVERSITY OF SOUTH FLORIDA}

\section{Revista Surco Sur}

Volume 7 | Issue 10

Article 13

$5-22-2017$

\title{
Entrevista a la escritora cubana María Elena Llana
}

Rocío Vélez Pesante

Follow this and additional works at: https://digitalcommons.usf.edu/surcosur

\section{Recommended Citation}

Vélez Pesante, Rocío. 2017. Entrevista a la escritora cubana María Elena Llana. Revista Surco Sur, Vol. 7: Iss. 10, 37-39.

DOI: http://dx.doi.org/10.5038/2157-5231.7.10.12

Available at: https://digitalcommons.usf.edu/surcosur/vol7/iss10/13

This CONVERSA(oye)NDO is brought to you for free and open access by the Open Access Journals at Digital Commons @ University of South Florida. It has been accepted for inclusion in Revista Surco Sur by an authorized editor of Digital Commons @ University of South Florida. For more information, please contact digitalcommons@usf.edu. 


\section{Dos escritores caribeños entrevistados}

\section{Rocío Vélez Pesante dialoga con María Elena Llana}

Como parte de una gira literaria por los Estados Unidos, la escritora cubana María Elena Llana fueinvitada a la Universidad del Sur deFlorida por el Departamento delnglésy el Departamento de World Languages. María Elena Llana nació en Villa Clara, Cuba en el 1936. Cursó su educación universitaria en periodismo en la Habana, por el que terminó como corresponsal cultural en muchos países, como también profesora de periodismo. Su primera publicación, en el 1965, dio paso a una exitosa y reconocida carrera literaria. Sus cuentos han sido tema central de tesis de maestría y doctorado en múltiples universidades. En la entrevista, Llana discute su trayectoria como escritora y periodista, su análisis sobre la antología Casas del V edado y de sus próximos proyectos.

¿En qué momento nace su interés por lo fantástico y que le proporciona este género a su expresión literaria?

Un día se me ocurrió un cuento fantástico y lo escribí. Pero pensé que este género no le interesaba a Cuba en ese momento. Las editoriales estaban vueltas para cosas más de la historia reciente, porque todo fue sobre los años 60 . Entonces l o guardé, pero cuando llegaba el momento de publicar un libro, ya tendría suficientes para publicar. Dividí el libro en tres secciones y una era como si fuera los divertimentos. Los cuentos eran un poco experimental, un poco raro, e incluí un cuento que se llama "Nosotras" que es, ya dentro de la categoría de lo fantástico, un cuento del doble. Entonces de pronto este cuento empezó a ser publicado, traducido y ser parte de antologías. A mí me divirtió tanto hacerlo. Tuvo tanto éxito que decidí que eso era lo que iba a hacer.

Lo fantástico en sí, te obliga a expresar lo fantástico. Para que lo increíble sea creíble, o sea, por lo menos lo aceptado por el lector, tiene que tener un andamiaje interior muy apretado. No se puede dejar cabo suelto porque entonces se destruye el cuento. La intención es que cuando tú lo leas, pienses: "A h ¿pasó esto?" pero ¿por qué pasó? Ah por esto y por esto". Eso es divertido, lo fantástico, lo psicológico del lector. Es un cuento que requiere una estructura muy sólida que no puede dejar nada al descubierto.

H ablando de su libro Casas del Vedado ¿Qué papel juega en esta antología, la especificación de las casas de ese lugar en los cuentos?

El Vedado fue un barrio emblemático dela burguesía cubana, aunque hubiera uno de más alta burguesía que es actualmente el barrio

Playa, Miramar. El Vedado tenía muchos centros culturales y por eso tenía más vida cultural. A hí también estaban las grandes residencias de la sociedad cubana. En la parte de Miramar estaban las casas más modernas, pero en

Vedado estaban las casas más tradicionales, la del gusto de la república. Entonces, cuando comienza ya el éxodo por la revolución, esas grandes mansiones se quedan vacías. Pero hay un grupo que no se va, bien porque están muy viejos o por quelosha dejado la familia. Ellos se quedan en sus grandes mansiones y entonces se refugian en ellas, es como si 

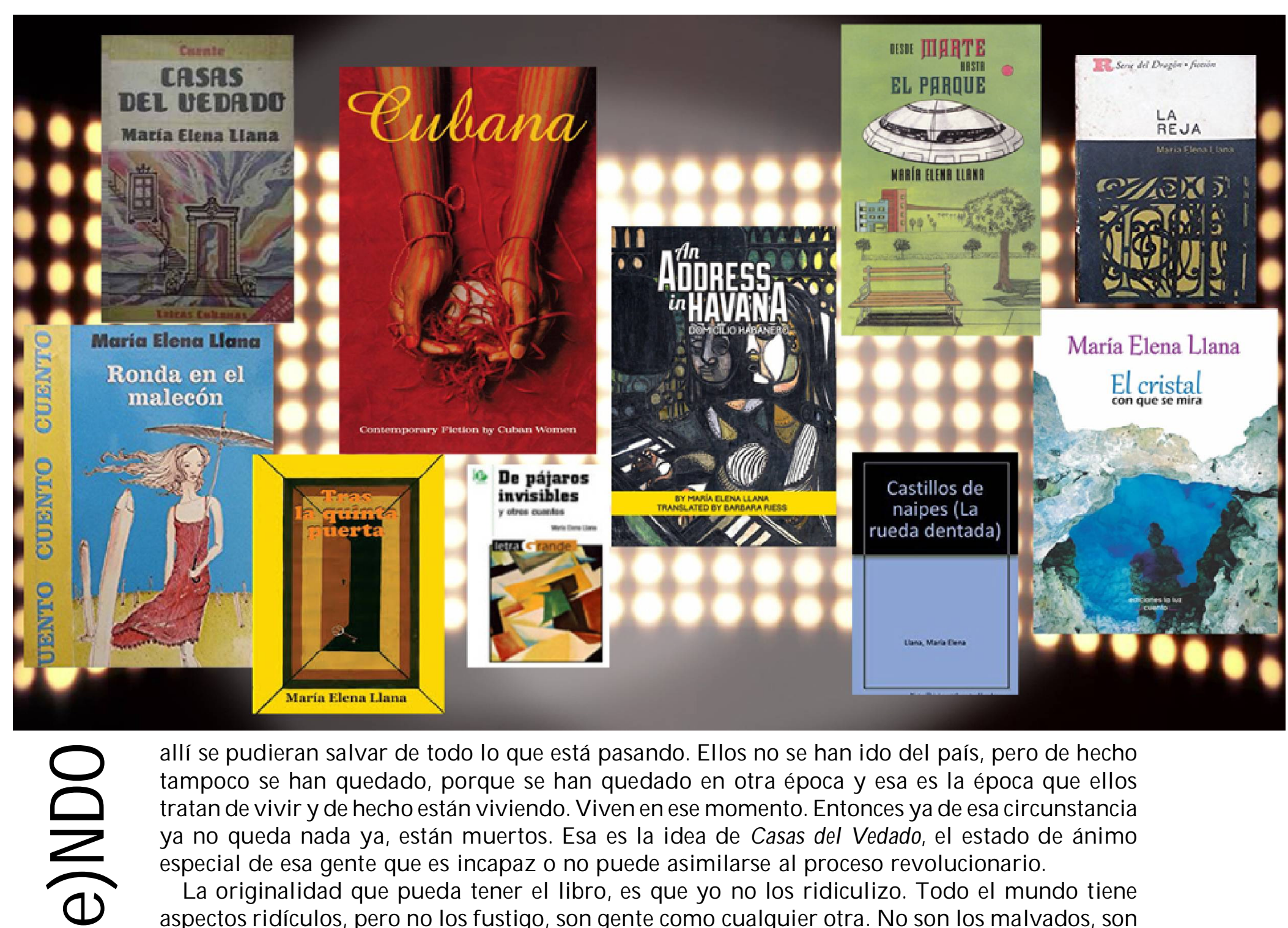

allí se pudieran salvar de todo lo que está pasando. Ellos no se han ido del país, pero de hecho tampoco se han quedado, porque se han quedado en otra época y esa es la época que ellos tratan devivir y dehecho están viviendo. Viven en ese momento. Entonces ya de esa circunstancia ya no queda nada ya, están muertos. Esa es la idea de Casas del Vedado, el estado de ánimo especial de esa gente que es incapaz o no puede asimilarse al proceso revolucionario.

La originalidad que pueda tener el libro, es que yo no los ridiculizo. Todo el mundo tiene aspectos ridículos, pero no los fustigo, son gente como cualquier otra. No son los malvados, son los que se quedaron y san se acabó.

¿Cuáles han sido sus influencias literarias, o aquellas obras que siempre vuel ve a releer?

El argentino Juan Bianco, tiene un cuento fantástico que se llama "Sombras suele vestir". Ese cuento fue el que me hizo decir: esto es lo que quiero escribir. Escribir es un don, tú lo tienes o no lo tienes. Después lo manejas, lo perfeccionas, le das la vuelta, pero lo tienes que tener. Es como hacer música o pintar.

En Casas del Vedado además de una hegemonía económica de clase media y alta en las mujeres de la narración, también vemos quetodas estas mujeres se sienten atadas a la casa u objetos que se encuentran en ella. ¿Por qué?

Hay una sobrevaloración de los objetos y de la simpatía con los objetos que nace de: "esto me recuerda a esta época" o "aquel momento que yo fui tan feliz que ya no va a volver". Son un poco el símbolo de su mundo lo que ya no van a encontrar, lo que se quedó ahí hablándole de otros tiempos. En mi cuento “La heredada”, que se llama así porque la prima rica está sola, no tiene quien le ayude en la casa y llama a su prima pobre que venga a vivir con ella. Esta señora es una extraña que se siente inferior por las propiedades de su prima. Entonces la prima rica se muere y el cuento se llama "La heredada" porque la prima pobre no heredó los objetos, los objetos la heredaron a ella. Ellos son los dueños.

El cuento "En familia" ten emos a la prima dela narradora, Clarita, que aun con preparación académica se queda en la casa con las otras mujeres de la familia. ¿Por qué?

Eso pasaba mucho en Cuba antes de la revolución. La revolución fue un parte aguas, un sacudimiento y ahí es cuando la mujer toma más participación. A ntes era esa tradición española. 
La mujer era para el hogar, no importa que fuera académica o lo que tú quieras. Clarita sigue ese esquema. Y lo dice el libro claramente, que Clarita fuera del lado de acá o el de la fantasía, después de morirse ella no había cambiado en nada su vida. Sientes que son vidas planificadas desde que nacen hasta la tumba. No pasa nada, siempre lo mismo, es un poco el estatismo de una sociedad. La metáfora puede ser que todo esto ocurrió en nuestro país, la fuerza para estremecer ese estatismo y romper ese estatismo. Eso es también una forma de ver la sociedad e incluso la política. Es un punto de vista grato, casi cotidiano. Porque también resulta que la literatura se vuelve un discurso, no tengo que darle clases a nadie. Yo digo fantasmagóricamente lo que quiero decir. No estoy ida de la realidad, esa es mi realidad.

Del 1983 con Casas del Vedado a Castillos de naipes, publicado en el 1998, hubo muchos cambios. En un artículo de José M iguel Sardiñas Fernández sobre su obra, se nombró una mayor participación de los personajes masculinos, la presencia de la nostalgia tanto como el del humor, y la inclusión de otro espacio de desarrollo narrativo en las provincias de Cuba. ¿A qué se debió este gran cambio?

Son fenómenos propios de la madurez. De un libro a otro hay muchos años. En Casas del $\checkmark$ edado yo guardaba lo que escribía porque ese tipo de literatura no se publicaba en Cuba. Esos temas habían sido expatriados por las editoriales. Es una época incluso en que casi ninguna mujer escribe, todos son hombres. En lo que se llama la "literatura de la violencia", todo eran guerras, planes agrícolas y fábricas. Yo pude escribir de todo eso porqueera periodista y conocía como era todo eso, aunque no me interesaba. Que lo digan ellos si quieren, a mí no me interesa hablar de eso, yo no voy a decir lo mismo.

¿Porque es que dentro del periodismo que usted hablaba de esos temas populares, como la guerra, pero se abstiene de ello en su literatura?

Mis libros fueron mi refugio para mí misma, para verme yo misma fuera de todo contexto. Realmente, Casa del V edado lo escribí sin esperanzas de que se publicara. Ese período de publicaciones de temas de guerras y demás, los estudiosos lo han Ilamado el "Quinquenio gris" porque no dejó casi nada de claridad. Después que pasó ese período, por lo menos ya habían opciones: la ciencia ficción, real ismo sucio (que no escribiría, pero es una tendencia descarnada, muy cruda, de la realidad de la vida), y todo eso se manifiesta. Incluso la ciencia ficción donde hay buenos escritores jóvenes.

¿Qué opina del futuro de la literatura cubana?

Hay una presencia real de la mujer en la literatura cubana, una reconocida y estimada. La temática es muy variada, muy diversa, al igual que los estilos: están las formas tradicionales de escritura y esta la experimentación. Realmente hay de todo. Y sobre todo tenemos la más recién jornada de jóvenes que es muy fuerte.

¿En qué está trabajando en la actualidad?

A cabo de terminar un libro que debería salir el año que viene que es de humor negro. Siempre he hecho humor sin proponérmelo, espero que ahora que me lo propongo, sea humor. En el periodismo en Cuba sigo haciendo crónicas literarias, comentarios de libros y entrevistas. 